\title{
Research and Algorithm Improvement of Permanent Magnet Synchronous Motor Direct Torque Control
}

\author{
Gang Wang \\ Sichuan Information Technology College, Guangyuan 628017, China \\ 18493621@qq.com
}

\begin{abstract}
Keywords: Permanent magnet synchronous motor, direct torque control, data simulation, PID control
\end{abstract}

\begin{abstract}
Permanent Magnet Synchronous Motor (PMSM) has been widely used in many fields for its advantages of small size, high efficiency, simple structure and low noise. In order to further improve performance of PMSM, it is necessary to do further research of its control strategy. Therefore, this paper mainly studied the direct torque control (DTC) strategy and its improved algorithm of PMSM. In this paper, we first introduce the mathematical model of PMSM and the zero vectors DTC, and then compares the traditional PID controller and the new adaptive PID controller. In order to better explain the problem, this paper makes a comparative simulation of the traditional DTC and the zero vectors DTC and the simulation results are shown in figure 1-8. By analyzing the results, we can find that the simulation that the flux waveform, three phase current waveform, the electromagnetic torque waveform, the speed waveform and the pulse of the DTC control with zero vectors have been improved obviously. In response time, the two can respond more quickly. So, this fully proves the superiority of the zero vector DTC control. And at the same time, we make a comparative simulation of the traditional PID control and the new PID control, and the simulation results are shown in figure 8- Figure 11. By analyzing and comparing the simulation results, we can find that the torque and speed pulse of the new adaptive PID controller is smaller, and its response time is shorter, and its anti-interference ability is stronger, and the steady state performance of the motor is improved remarkably.
\end{abstract}

\section{INTRODUCTION}

Magnetic synchronous motor (PMSM) has the advantages of small size, simple structure, light weight, high efficiency, large torque inertia ratio and so on [1]. Compared with DC motor, it has no brush DC (direct current) motor and the commentator, which avoids a series of problems brought by this. Compared with the induction motor, the PMSM does not need exciting current, so its power factor is high, and the active power loss of the stator resistance is small, and the rotor parameters can be measured, and the control performance is better [2]. Compared with the common synchronous motor, the permanent magnet synchronous motor saves the excitation device, simplifies the system structure and improves the efficiency. Permanent magnet synchronous motor system with advanced control algorithms, such as vector control or direct torque control, can achieve high precision and wide range of speed regulation or positioning control, and its dynamic performance is good. Therefore, permanent magnet synchronous motor has been more and more widely used in various fields [3].

In 1980s, Japanese scholar Takahashi I and German scholar Depenhrok M proposed the direct torque control (DTC) for asynchronous motor for the first time. The control of the motor in the speed control system is essentially the control of the motor torque, and DTC is a direct torque control target, through the use of torque and flux linkage double closed loop structure to obtain fast torque response. It is another important AC speed regulation control strategy after the vector control. The main idea is to select the appropriate stator voltage space vector directly according to the torque and flux linkage of the motor. Compared with vector control, DTC has the advantages of simple structure, fast response, and strong robustness to parameter variation and so on. It is mainly used in the induction motor, and the application of PMSM in the induction motor has to be further studied $[4,5]$. Because the method does not need the complex rotational coordinate transformation, the 
parameter dependence of the motor is low, and its robustness is good. Therefore, it has aroused wide attention since it was put forward. Later on the basis of the traditional DTC, a number of improvements have been made, such as adding a zero vector function in the traditional direct torque to reduce the torque ripple in the control process. In this paper, the neural network control is applied to the PID control system, so as to enhance the robustness of the system, further reducing the torque ripple, and improve the steady state performance of the motor.

\section{RESEARCH CONTENTS}

\subsection{PMSM mathematical model}

The expression of the voltage, torque and stator flux linkage in the and $\beta$ coordinates of the PMSM is as follows [6]:

$$
\begin{aligned}
& \left\{\begin{array}{l}
U_{a}=R i_{a}+L_{s} \frac{d i_{a}}{d t}-\omega_{x} \psi_{f} \sin \theta_{x} \\
U_{\beta}=R i_{\beta}+L_{s} \frac{d i_{\beta}}{d t}-\omega_{x} \psi_{f} \sin \theta_{y}
\end{array}\right. \\
& T_{e}=\frac{3}{2} p_{n}\left(\psi_{s \beta} i_{a}-\psi_{s \mathrm{sa}} i_{\beta}\right) \\
& \left|\psi_{s}\right|=\sqrt{\left(\psi_{s a}{ }^{2}+\psi_{s \beta}{ }^{2}\right)}
\end{aligned}
$$

In the above formula: $U a$ is the $\alpha$ component of the stator voltage; $U \beta$ is the $\beta$ axis component of the stator voltage; $i$ a is the alpha a component of the electric current; $U \beta$ is the $\beta$ axis component of the electric current; $\psi_{s a}$ is the alpha a component of the flux linkage; $\psi_{s \beta}$ is the $\beta$ axis component of the flux linkage; Te is electromagnetic torque; $p$ is the logarithm of the motor; $\left|\psi_{s}\right|$ is the amplitude of stator flux linkage; $\psi \mathrm{f}$ is the rotor flux.

After Park transformation, the flux linkage and torque equations are obtained in the $\mathrm{d}$-q rotating coordinate system

$$
\left\{\begin{array}{l}
\psi_{d}=\psi_{f}+L_{s} i_{d} \\
\psi_{q}=L_{s} i_{q}
\end{array}, T_{e}=\frac{3}{2} p \psi_{f} i_{q}\right.
$$

In the above formula: id is the d component; iq is the qaxis component; Ls is the stator inductance.

\subsection{DTC with zero vectors}

After the zero vectors are acting on the motor, the torque of the motor is mainly decided by the speed of the motor. When the motor is kept at low speed [7], the A is small, the torque of the zero vectors is less, and the torque of the motor is basically unchanged, so that the torque ripple is reduced. Through the control effect of the zero vectors on torque under different speed, the maximum value of the motor torque change is significantly smaller than the maximum value of the torque change. After introducing the zero vector into the torque regulator, the mathematical model of the flux linkage and torque regulator is introduced:

$$
\varphi=\left\{\begin{array}{l}
1,\left|\psi_{s}^{*}\right|-\left|\psi_{s}\right|>0 \\
0,\left|\psi_{s}^{*}\right|-\left|\psi_{s}\right|<0
\end{array}, T=\left\{\begin{array}{l}
1, T_{e}<T_{e}^{*}-\Delta T_{\text {eff }} \\
0,\left|T_{e}-T_{e}^{*}\right| \leq \Delta T_{\text {eff }} \\
-1, T_{e}>T_{e}^{*}+\Delta T_{\text {eff }}
\end{array}\right.\right.
$$

In the above formula: $\Delta$ Teff is the zero vector scope.

When $\mathrm{T}=1$, the lower limit of the scope of the action is beyond the scope of the zero vector, and the role of nonzero vectors should be increased; when $T=0$, it shows that the torque error is within the scope of the zero vector, and we should choose the zero vector acting on the regulator;; when $\mathrm{T}=-1$, that has been beyond the zero vector function of the upper limit of the range, non-zero vector function should be reduced.

\subsection{New adaptive PID control}

The traditional PID control is a linear controller, which can control the input quantity by the linear adjustment of the proportion, integral and differential, so as to output the appropriate output quantity. For nonlinear systems such as PMSM, the control effect of the traditional PID control in many cases is not ideal, and it needs to be repeated debugging to get the appropriate PID value [8, 9]. Single neuron adaptive PID controller is introduced in this paper, and the new PID controller based on 
intelligent control can adapt to the nonlinear system. It is adaptive to the system to achieve the ideal state of the system by self-learning. The output of single neuron PID controller is:

$$
U(k)=U(k-1)+A \sum_{i=1}^{3} u_{i}(k) x_{i}(k)
$$

In the above formula: $A$ is the ratio of neurons, and $A>0$; Ui $(k)$ is the weighted coefficient corresponding to the input $x i(\mathrm{k}) ; \mathrm{i}=1,2,3$ is actually expressed in integral, proportional and differential; so the weighting factor can be regarded as the gain of PID component [10]. It is equivalent to the weight of the input variable in the incremental PID control, and its formula is:

$$
u_{i}(k)=\frac{u_{i}(k)}{\sum_{i=1}^{3}\left|u_{i}(k)\right|}
$$

In addition, the weighted coefficient for correction formula:

$$
\begin{aligned}
& u_{1}(k+1)=u_{1}(k)+\lambda_{1} z(k) v(k) x_{1}(k) \\
& u_{2}(k+1)=u_{2}(k)+\lambda_{\mathrm{p}} z(k) v(k) x_{2}(k) \\
& u_{3}(k+1)=u_{3}(k)+\lambda_{D} z(k) v(k) x_{3}(k)
\end{aligned}
$$

In the above formula: $\lambda I$ represents the integral learning rate, $\lambda P$ represents the proportion of learning rate, $\lambda \mathrm{D}$ represents the differential learning rate; $\mathrm{z}(\mathrm{k})$ indicates the output error signal; $\mathrm{xi}$ represents the input variables of the system.

\subsection{Contrast simulation of traditional DTC and zero vector DTC}

In order to verify that when compared with ordinary DTC, the static performance of DTC with zero vectors is better, and the torque ripple of DTC with zero vectors is smaller, and its robustness is stronger, we make the modeling and Simulation in MATLAB / Simulink. PMSM parameters are as follows: stator resistance $r=1.18 \Omega$; Axis inductance $\mathrm{Ld}=\mathrm{Lq}=3.85 \mathrm{mH}$; Polar logarithm $\mathrm{pn}=4$. The starting load torque is $5 \mathrm{~N} \bullet \mathrm{m}$; the given flux amplitude is 0.3 ; given speed is $55 \mathrm{r} / \mathrm{min}$; the simulation time is $0.5 \mathrm{~s}$.

2.5 Contrast simulation of traditional PID and new adaptive PID

In this comparative analysis, we also use the parameters of the permanent magnet motor: stator resistance $r=1.18$; Axis inductance $\mathrm{Ld}=\mathrm{Lq}=3.85 \mathrm{mH}$; Polar logarithm $\mathrm{pn}=4$. The starting load torque is; the given flux amplitude is 0.3 ; given speed is $55 \mathrm{r} / \mathrm{min}$; the simulation time is $0.5 \mathrm{~s}$. Under the MATLAB / Simulink software, we analyze the containing new adaptive PID controller in direct torque three-phase stator current, electromagnetic torque and speed waveform control, and with the conventional PID controller in the direct torque control simulation waveforms are compared. According to the above formula, we construct a new adaptive PID module on the basis of the zero vector DTC model, and expressed by s function method.

\section{RESEARCH RESULTS AND DISCUSSION}

\subsection{Simulation results and analysis of traditional DTC and zero vector DTC}

Figure 1 to Figure 8 shows the flux linkage, stator three-phase current, electromagnetic torque and speed of the simulation waveform.

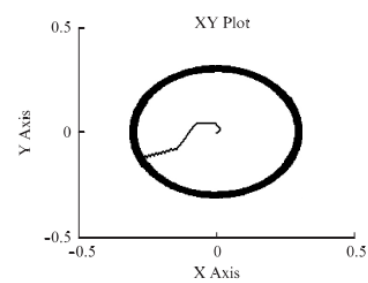

Fig.1 Traditional DTC stator flux waveform

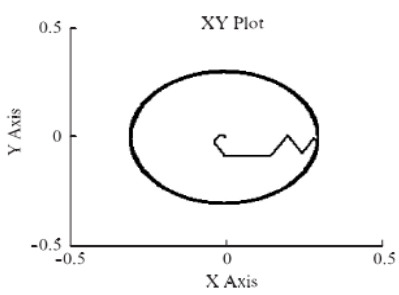

Fig.2 DTC stator flux waveform with zero vector 


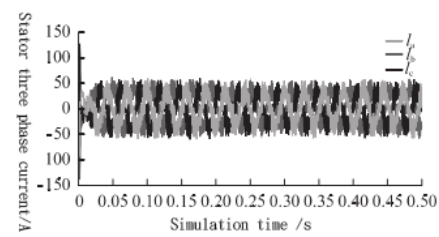

Fig.3 Traditional DTC stator three phase current waveform

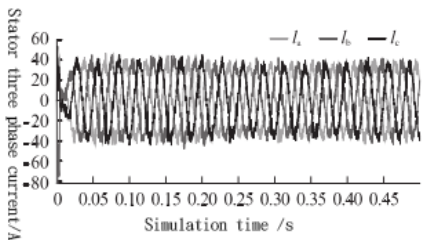

Fig.4 DTC stator three phase current waveform with zero vector

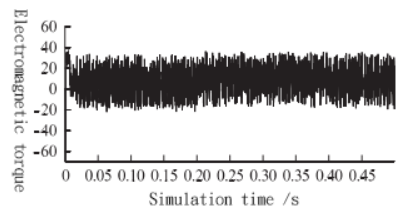

Fig.5 Electromagnetic torque waveform of traditional DTC.

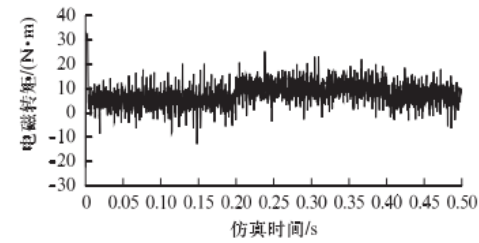

Fig.6 DTC electromagnetic torque waveform with zero vector

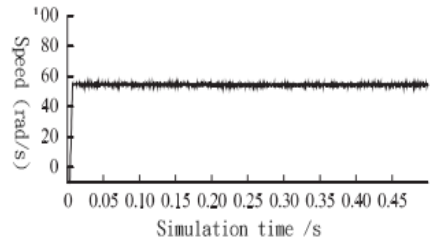

Fig.7 Rotational speed waveform of traditional DTC.

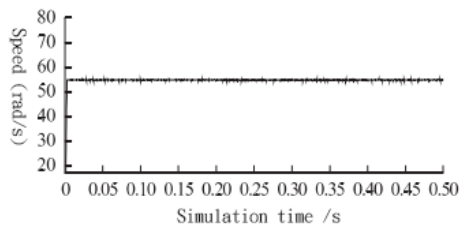

Fig.8 DTC Speed waveform of DTC with zero vector

It can be seen from the simulation that the flux waveform, three phase current waveform, the electromagnetic torque waveform, the speed waveform and the pulse of the DTC control with zero vectors have been improved obviously. In response time, the two can respond more quickly. So, this fully proves the superiority of the zero vector DTC control.

\subsection{Simulation results and analysis of traditional PID and new PID}

The direct torque control stator three-phase current, electromagnetic torque and rotational speed waveform of the new adaptive PID controller are shown in the following figure.

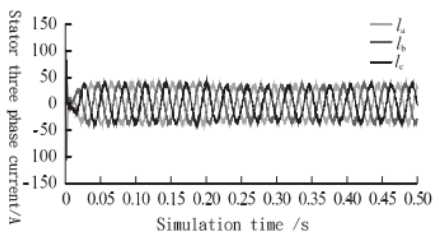

Fig.9 Stator three phase current waveform 


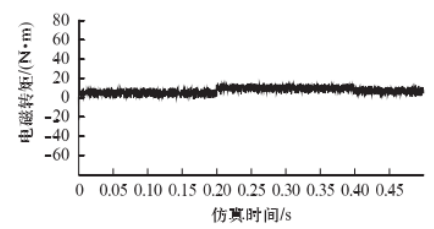

Fig.10 Electromagnetic torque waveform

In contrast to the above shows, the PID contains a new adaptive DTC has a smaller torque ripple after the system enters the steady state, and the speed fluctuation has a significant decline compared with before. It is also more rapid in response time, and the three phase current waveform is also closer to the complete sine wave. This shows that the new adaptive PID controller has the characteristics of small torque ripple, small speed error, and more rapid response in the steady state of the motor.

\section{CONCLUSIONS}

Through the theoretical analysis and numerical simulation results, we can find that in the MATLAB simulation environment, the pulse of DTC with zero vector is smaller compared with the traditional DTC from the point of view of torque and rotational speed, and because PMSM has the characteristics of nonlinear, strong coupling, traditional PID control cannot achieve the ideal effect in terms of control, and single neuron PID control can be used to control nonlinear system. But in the steady state, there is a large error in the control of single neuron PID, and a novel adaptive PID controller is designed by combining the traditional PID with the single neuron PID. After analyzing the simulation results, we find that the torque and speed pulse of the new adaptive PID controller is smaller, and its response time is shorter, its anti-interference ability is stronger, and the steady state performance of the motor is improved remarkably.

\section{REFERENCES}

[1] Yang Y, Chen X, Xiao-Wei T U, et al. Direct torque control of permanent magnet synchronous motor based on duty ratio control [J]. Electric Machines \& Control, 2014.

[2] Azizi I, Radjeai H. Direct Torque Control Method of Permanent Magnet Synchronous Motor with Speed Control [J]. Australian Journal of Basic \& Applied Sciences, 2013.

[3] Moujahed M, Ben Azza H, Jemli M, et al. Sensor-less direct torque control of permanent magnet synchronous motor drive using Extended Kalman filter[C]// Electrical Engineering and Software Applications (ICEESA), 2013 International Conference on. IEEE, 2013:1-5.

[4] Cho Y, Kim D H, Lee K B, et al. Torque ripple reduction and fast torque response strategy of direct torque control for permanent-magnet synchronous motor [J]. Immunology Today, 2013, 10(12):1-6.

[5] Zhong T Y, Mao J, Zhou Y Z. Direct torque control for permanent magnet synchronous motor based on inverse system decouple theory [J]. Journal of Fuzhou University, 2014.

[6] Wang X, Xing Y, Yu H L, et al. Permanent magnet synchronous motor direct torque control based on Particle Filter observer[C]// Control and Decision Conference (2014 CCDC), The 26th Chinese. IEEE, 2014:1606-1609.

[7] Tu X W, Yang Y, Chen X, et al. Direct Torque Control Servo System for Permanent Magnet Synchronous Motor [M]. Applied Mechanics and Materials, 2013.

[8] Zhou X, Wu C, Zhang S. Research on direct torque control for permanent magnet synchronous motor drives[C]// Electrical Machines and Systems (ICEMS), 2014 17th International Conference on. IEEE, 2014.

[9] Zhao S, Liang J, Zhao Y. Optimization Design and Direct Torque Control of a Flux Concentrating Axial Flux Permanent Magnet Motor for Direct Driving System[J]. Electric Power 
Components \& Systems, 2014, 42(42):1517-1529.

[10] Lu C F, Yu H B. Research on Direct Torque Control Adaptive Fuzzy Neural Network Controller of Permanent Magnet Synchronous Motor[J]. Advanced Materials Research, 2014, 989-994:2815-2819. 